\title{
Smoking as a contributing cause of death in Wisconsin, United States, 1990
}

\author{
Gianfranco Pezzino, Patrick L Remington, Henry A Anderson, Larry P Hanrahan, \\ Dan E Peterson
}

\begin{abstract}
Objective - To investigate the frequency of smoking as a listed cause of death for selected lung diseases on death certificates.

Design and setting-Population-based descriptive and case-control study. Deaths, next of kin, and certifying physicians were identified from the state death certificate database. Smoking history of the decedents was ascertained through a questionnaire mailed to the next of kin.

Participants - All deaths from smokingrelated lung diseases in Wisconsin in 1990. In the case-control study, cases were defined as deaths in which death certificates listed smoking as a contributing cause of death. Controls were defined as deaths in which smoking was not mentioned on the death certificates.
\end{abstract}

Main outcome measure-Presence of the ICD-9 code 305.1 (tobacco use disorder) on a death certificate.

Results - While epidemiologic evidence indicates that smoking contributed to $80 \%$ of these deaths, it was mentioned as a contributing cause of death in only 263 (7\%) of the 3866 certificates examined. Females, rural residents, and more educated persons were more likely to have smoking listed as a cause of death. Older physicians and oncologists were less likely to list smoking as a cause of death. The case-control study showed that among controls (whose certificate did not mention smoking), almost half were heavy life-time smokers and more than one-third were smokers at the time of death.

Conclusions-Physicians infrequently listed smoking on the death certificate, even when smoking was likely to have contributed to the death. A more accurate recording of smoking as a cause of death would improve the usefulness of death certificates for epidemiologic research and public health practice.

(Tobacco Control 1994; 3: 120-123)

\section{Introduction}

While epidemiologic evidence indicates that smoking is a risk factor in about $20 \%$ of all deaths, ${ }^{1,2}$ only less than $1 \%$ of US death certificates mentioned smoking as an underlying or contributing cause of death in $1980 .^{3}$ The reasons for this discrepancy are not well understood. We therefore examined Wisconsin death certificates to evaluate the practice of listing smoking as a cause of death.

\section{Methods}

We searched the $1990 \mathrm{~W}$ isconsin computerised death certificates data set for the presence of the code 305.1 ("tobacco use disorder") from the International Classification of Diseases (ICD-9). ${ }^{4}$ We linked these death certificates, which contained the certifier's name, with the Wisconsin State Office of Licensing database, which contains the age, gender, and specialty of physicians licensed in the state.

We limited our analysis to three lung diseases that have been widely associated with smoking: lung cancer (ICD 162, "Malignant neoplasm of trachea, bronchus, and lung"), chronic airway obstruction (ICD 496, "Chronic airway obstruction, not elsewhere classified"), and bronchitis/emphysema (ICD 491, "Chronic bronchitis", and 492, "Emphysema"). For each of these disease categories, epidemiologic studies indicate that more than $80 \%$ of deaths are due to smoking. ${ }^{1}$

We divided our investigation into a descriptive study of all deaths due to the three lung diseases and a case-control study of a subset of these deaths.

\section{DESCRIPTIVE STUDY}

We compared decedent and certifier characteristics on the certificates listing smoking to those on the certificates not listing smoking. We analysed the data by univariate analysis and by logistic regression, to control simultaneously for the effects of several decedent and certifier characteristics.

\section{CASE-CONTROL STUDY}

The purpose of the case-control study was to ascertain the smoking history of the decedents, as reported by the next of kin, and to analyse the relationship between smoking history and the mention of smoking on the death certificate.

We defined a case as a death that occurred in 1990 in Wisconsin from one of the lung diseases listed above, in which the death certificate contained the code 305.1 as a 
contributing cause of death. (Nosological algorithms almost always classify any mention of tobacco use as a contributing, rather than an underlying, cause of death.) Controls were selected from deaths from the same diseases, but in which the certificate did not contain the code 305.1. The same number of cases and controls were frequency matched by underlying cause of death, age (within 5 years), and gender, because these factors could be associated with smoking and could also influence the likelihood of physicians to report smoking as a cause of death.

In July 1992, we mailed a questionnaire to the next of kin of each decedent (identified from the death certificate) and asked about the smoking history of the person who died. We mailed 526 questionnaires (263 cases and 263 controls); 57 (11\%) were returned by the US postal service as undeliverable (20 cases and 37 controls). Of the remaining 469 delivered questionnaires, we received a response for 332 $(71 \%)$. Demographic and matching characteristics of case and control respondents were similar (table 1).

Ever-smokers were defined as people who smoked at least 100 cigarettes during their lifetime. Current smokers were defined as people who never stopped smoking or who had stopped less than one year before death. Heavy life-time smokers were defined as people who smoked 50 or more pack-years (a pack-year is the number of packs smoked per day multiplied by the number of years that person smoked, with one pack $=20$ cigarettes).

\section{Results}

DESCRIPTIVE STUDY

Of the 3866 death certificates in which death was due to the lung diseases included in our study, $263(7 \%)$ listed smoking as a contributing cause of death (table 2). Of the 1616 physicians who wrote at least one of these certificates, $177(11 \%)$ listed smoking as a contributing cause at least once.

People living in rural areas (areas not included in any US Bureau of Census Metropolitan Statistical Areas) and people with more

Table 1 Respondent characteristics, by case-control status and matching variables

\begin{tabular}{|c|c|c|}
\hline Characteristic & $\begin{array}{l}\text { Percent of } \\
\text { cases }^{a} \\
(n=170)\end{array}$ & $\begin{array}{l}\text { Percent of } \\
\text { controls } \\
(n=162)\end{array}$ \\
\hline \multicolumn{3}{|l|}{ Age (years): } \\
\hline & 5 & 5 \\
\hline $\begin{array}{l}55-64 \\
65-74\end{array}$ & 14 & 14 \\
\hline $\begin{array}{l}65-74 \\
<74\end{array}$ & 38 & 44 \\
\hline \\
\hline $\begin{array}{l}\text { Gender: } \\
\text { Female }\end{array}$ & & \\
\hline Male & 62 & 56 \\
\hline \multicolumn{3}{|l|}{ Cause of death: } \\
\hline Lung cancer & 49 & 50 \\
\hline Chronic airway & 35 & 38 \\
\hline $\begin{array}{l}\text { Bronchitis/ } \\
\text { emphysema }\end{array}$ & 16 & 12 \\
\hline
\end{tabular}

${ }^{a}$ Cases were defined as deaths in which smoking was listed as a contributing cause on the death certificate.

${ }_{b}$ Controls were defined as deaths in which smoking was not listed as a contributing cause on the death certificate.
Table 2 Percentage of selected lung disease deaths with smoking listed as a contributing cause, by cause of death (Wisconsin, USA, 1990)

\begin{tabular}{lll}
\hline $\begin{array}{l}\text { Cause of } \\
\text { death }\end{array}$ & $\begin{array}{l}\text { Number } \\
\text { of deaths }\end{array}$ & $\begin{array}{l}\text { Number } \\
\text { with smoking } \\
\text { listed }(\%)\end{array}$ \\
\hline $\begin{array}{l}\text { Lung cancer } \\
\begin{array}{l}\text { Chronic airway } \\
\text { obstruction }\end{array}\end{array}$ & 2407 & $131(5)$ \\
$\begin{array}{l}\text { Bronchitis/ } \\
\text { emphysema }\end{array}$ & 349 & $93(8)$ \\
Total & 3866 & $39(11)$ \\
\hline
\end{tabular}

than a high school education were more likely than urban residents and those with less education to have smoking mentioned on their death certificates (table 3). Younger physicians, family practitioners, internists, and chest disease specialists were most likely to list smoking.

\section{CASE-CONTROL STUDY}

Information on smoking was reported by the next of kin for $153(90 \%)$ cases and $153(94 \%)$ controls (table 4). Among cases, all but two $(99 \%)$ were ever-smokers, $51 \%$ were current smokers, and $64 \%$ were heavy life-time smokers. Controls were less likely to be smokers : $90 \%$ were ever-smokers, $37 \%$ were current smokers, and $46 \%$ were heavy lifetime smokers ( $p<0.01$ for all three categories).

\section{Discussion}

Physicians infrequently list smoking as a contributing cause of death, even for lung diseases for which smoking is a widely recognised cause. According to the US Surgeon General, smoking is responsible for at least $80 \%$ of the deaths from the causes examined in our study. ${ }^{1}$ Despite this, it was mentioned on only $7 \%$ of the death certificates, and only $11 \%$ of physicians certifying these deaths listed smoking as a contributing cause of death.

Our case-control study shows that this discrepancy is due to physicians failing to report the role of smoking as a cause of death. Among people dying from these lung diseases and whose death certificate did not mention smoking, almost half were heavy life-time smokers and more than one-third were current smokers at the time of death.

Younger physicians were more likely to mention smoking on the death certificates. This may represent differences in the training of recent graduates, or changes in practice with increasing time in clinical practice. In addition, the slightly higher rate of listing smoking by family practitioners and for people living in rural areas, women, and those with more education, may reflect differences in the health care setting and in the continuity of the contact between patients and physicians, which in turn may make it easier for the certifier to ascertain the role of behavioural factors such as smoking in causing the death.

One limitation of our study is that smoking histories were based only on a report of the 
Table 3 Percentage of lung disease deaths ${ }^{a}$ with smoking listed as a contributing cause, by selected patient and certifier characteristics. Wisconsin, USA, 1990

\begin{tabular}{|c|c|c|c|}
\hline Characteristic & $\begin{array}{l}\text { Number of deaths } \\
\quad(n=3866)\end{array}$ & $\begin{array}{l}\text { Percent with } \\
\text { smoking listed } \\
\quad(n=263)\end{array}$ & $\begin{array}{c}\text { Adjusted RR } \\
\left(95 \% C I^{b}\right.\end{array}$ \\
\hline \multicolumn{4}{|l|}{ Patient age (years) } \\
\hline$<55$ & 259 & 7 & REF \\
\hline $55-64$ & 689 & 4 & $0.7(0.4-1.3)$ \\
\hline $65-74$ & 1272 & 9 & $1.2(0.7-2.2)$ \\
\hline $\begin{array}{l}75+ \\
\text { Patient gender }\end{array}$ & 1646 & 6 & $0.9(0.5-1.5)$ \\
\hline \multicolumn{4}{|l|}{ Patient gender } \\
\hline $\begin{array}{l}\text { Males } \\
\text { Females }\end{array}$ & $\begin{array}{l}2486 \\
1380\end{array}$ & $\begin{array}{l}6 \\
8\end{array}$ & REF \\
\hline \multicolumn{4}{|l|}{ Patient residence ${ }^{c}$} \\
\hline Urban & 2444 & 6 & REF \\
\hline Rural & 1332 & 8 & $1.4(1.1-1.8)$ \\
\hline \multicolumn{3}{|c|}{ Patient education $\left(\right.$ years $^{c}$ ) } & \\
\hline$<_{12}^{12}$ & $\begin{array}{l}1739 \\
1490\end{array}$ & $\begin{array}{l}6 \\
6\end{array}$ & $\stackrel{\text { REF }}{0.6-12)}$ \\
\hline$>12$ & 607 & $\begin{array}{r}0 \\
10\end{array}$ & $\begin{array}{l}0.9(0.0-1.2) \\
1.6(1.2-2.3)\end{array}$ \\
\hline \multicolumn{4}{|l|}{ Certifier } \\
\hline Coroner & 347 & 3 & REF \\
\hline Physician & 3519 & 7 & $2.0(0.9-4.3)$ \\
\hline \multicolumn{4}{|l|}{ Physician specialty ${ }^{c}$} \\
\hline Internal medicine & 1245 & 7 & REF \\
\hline Chest diseases & 140 & 20 & $3.0(1.8-4.8)$ \\
\hline Family practice & 883 & 11 & $1.4(1.1-2.0)$ \\
\hline General practice & 265 & 4 & $0.8(0.4-1.6)$ \\
\hline Surgery & 98 & 4 & $0.7(0.2-2.0)$ \\
\hline Oncology & 378 & 1 & $0.2(0.1-0.4)$ \\
\hline $\begin{array}{l}\text { Others } \\
\text { Physician age (yearsc }\end{array}$ & 462 & 4 & $0.5(0.3-0.9)$ \\
\hline \multicolumn{4}{|l|}{ Physician age (years ${ }^{c}$ ) } \\
\hline $\begin{array}{l}<41 \\
41-50\end{array}$ & $\begin{array}{l}1398 \\
1155\end{array}$ & 10 & $\frac{\text { REF }}{0.6(0.5-0.8)}$ \\
\hline $51-60$ & $\begin{array}{r}1135 \\
562\end{array}$ & $\begin{array}{l}0 \\
5\end{array}$ & $\begin{array}{l}0.6(0.5-0.8) \\
0.5(0.3-0.8)\end{array}$ \\
\hline$>60$ & 346 & 3 & $0.3(0.2-0.6)$ \\
\hline
\end{tabular}

REF = reference group

${ }^{a}$ Deaths from lung cancer, chronic airway obstruction, and bronchitis/emphysema.

${ }^{b}$ Relative risk (RR) and $95 \%$ confidence interval (CI) estimated after adjustment for the other variables in the table in a

logistic regression model.

Numbers based on the records for which the information was available.

Table 4 Smoking characteristics of the respondents, by case-control status

\begin{tabular}{lcc}
\hline Characteristic & $\begin{array}{c}\text { Percent of }_{\text {cases }^{a}} \\
(n=153)\end{array}$ & $\begin{array}{c}\text { Percent of } \\
\text { controls }^{b} \\
(n=153)\end{array}$ \\
\hline $\begin{array}{l}\text { Ever-smokers } \\
\text { Current smokers }\end{array}$ & 99 & 90 \\
Heavy life-time & 51 & 37 \\
smokers & 64 & 46 \\
\hline
\end{tabular}

a Cases were defined as deaths in which smoking was listed as a contributing cause of death on the death certificate. Controls were defined as deaths in which smoking was not listed as a contributing cause of death on the death certificate.

next of kin, and were collected up to two years after the death. This could cause inaccurate reports (which could explain the two cases for which the death certificate mentioned smoking, but the next of kin reported no smoking by the decedent). However, because cases and controls died from the same diseases and during the same period, a difference between cases and controls in the accuracy of the reported smoking history is unlikely.

Several reasons probably contribute to the infrequent mention of smoking on the death certificates. First, some physicians may not know that smoking can be listed as a cause of death on death certificates. The definition of code 305.1, which refers to "tobacco use disorders" under the general classification "non-dependent abuse of drugs", may be confusing. Physicians may also feel uncertain about listing a behavioural factor, smoking, which is different from the pathologic factors usually listed as causes of death. In addition, physicians may find it difficult to apply to individual deaths, relationships known to be true in population studies ("Yes, smoking causes lung cancer, but did it contribute to THIS lung cancer?"'). Finally, physicians may be unaware that information on death certificates regarding the role of tobacco can have important uses in public health.

A more accurate recording of tobacco use on the death certificates could have important uses in public health. Death certificates would reflect the actual burden of smoking in different communities better than the epidemiologic projections currently used. This information could be used for professional and public education, and could help sustain social and physician concern about the burden of cigarette smoking. Furthermore, the usefulness of death records for surveillance and epidemiologic research would be improved. For example, it would be possible to monitor trends in lung cancer among non-smokers, to determine the contribution of other environmental factors (besides smoking) to changes in lung cancer mortality.

The issue of how death certificates can better reflect the effects of smoking has been debated, both in the US and in other countries. In the US, several states have introduced alternative death certificate systems to assess the role of smoking. ${ }^{5}$ Some states have introduced separate questions on their death certificates that determine whether smoking was a contributing cause of that death. This system is similar to the current ICD system, where tobacco use can be mentioned as a cause of death, but it tries to elicit more information by openly 
asking the certifier about the possible role of smoking, and by offering a range of possible answers (eg, "Yes", "Probably yes", "No", "Unknown"). In Britain, since 1992 doctors have been allowed to mention smoking as a cause of death on the certificate without having to report the death to the coroner. ${ }^{6}$ Concerns have been raised (in Britain and elsewhere) about the reliability of this information, because of the difficulty in establishing in which individual deaths smoking might have been a contributing factor. ${ }^{7}$ An alternative system is to record only smoking history (ie, the risk behaviour). In this way, physicians are relieved from the task of having to decide in which specific deaths smoking was a contributing factor.

Preliminary reports suggest that these new systems are feasible and markedly increase the listing of tobacco as a cause of death. ${ }^{8}$ For example, the state of Oregon (where death certificates ask "Did tobacco use contribute to death?") published a report on mortality due to tobacco use (according to death certificates) by disease, age, geographic area, race, gender, and other characteristics. ${ }^{9}$ In most cases, the proportion of deaths attributed to smoking was remarkably close to what would be expected from epidemiologic projections. However, death certificates are legal, internationally standardised documents, and any change in their format may have important implications that should be carefully considered. The results of these new systems need to be evaluated, weighing the potential disadvantages against the advantages of improving the accuracy of death records and their usefulness in public health.
Our study shows the failure of the current medical practice to recognise and report the role of tobacco dependence as the leading preventable cause of mortality. Since death certificates remain a fundamental tool in epidemiology and in public health ${ }^{10,11}$ a more accurate recording of smoking as a cause of death is essential. ${ }^{3}$

We would like to thank Elise Jochimsen, for her help in planning the study and data entry; Harry Rosenberg and George Gay, National Center for Health Statistics, and Paul M Lantz, Marshfield Medical Research Foundation, for their comments.

1 US Department of Health and Human Services. Reducin the health consequences of smoking: 25 years of progress. $A$ report of the Surgeon General, 1989. Atlanta, Georgia Centers for Disease Control. Office on Smoking and Health, 1989. (DHHS Publication No (CDC) 89-8411.)

2 Shultz JM, Novotny TE, Rice DP: SAMMEC II. Smokin attributable mortality, morbidity, and economic costs. US Department of Health and Human Services, Public Dealth Service, Centers for Disease Control Center for Chronic Disease Prevention and Health Promoter for Office on Smoking and Health, April 1990

3 Pollin W, Ravenholt RT. Tobacco addiction and tobacco mortality. FAMA 1984; 252 : 2849-54

4 Manual of the International Classification of Diseases, Injuries and Causes of Death. Geneva, Switzerland: World Health Organisation, 1977

5 Silverman $S$. States modify certificate to meet specific needs. F $A M A 1989 ; 261: 2300-5$.

6 Beecham L. Smoking accepted on death certificates. $B M F$ 1992; 305: 543-4

7 Peto R, Doll R. Smoking accepted on death certificates. $B M F$ 1992; 305: 829-30.

8 McAnulty JM, Hopkins D, Grant-Worley J, Baron R, Fleming D. A comparison of alternative systems for measuring smoking-attributable deaths in Oregon. Proceedings of the 41 st Epidemic Intelligence Service annual conference. Centers for Disease Control, Atlanta, Georerence. Centers for

9 Hopkins D. Tobacco and Oregonians. A legacy of illness and death. Portland, Oregon: Oregon Department of Human Resources, 1992

10 Havlik RJ. The present and future of mortality statistics. NY State f Med 1990; 90: 440-1.

11 Rosenberg HM. Improving cause-of-death statistics. $A m$ Public Health 1989; 79: 563-4. 